\title{
On the Topotactic Transformation of Ti2AlC into a Ti-C-O-F Cubic Phase by Heating in Molten Lithium Fluoride in Air
}

\author{
Michael Naguib, Volker Presser, Darin Tallman, Jun Lu, Lars Hultman, \\ Yury Gogotsi and Michel W Barsoum
}

\section{Linköping University Post Print}

N.B.: When citing this work, cite the original article.

This is the authors' version of the following article:

Michael Naguib, Volker Presser, Darin Tallman, Jun Lu, Lars Hultman, Yury Gogotsi and Michel W Barsoum, On the Topotactic Transformation of Ti2AlC into a Ti-C-O-F Cubic Phase by Heating in Molten Lithium Fluoride in Air, 2011, Journal of The American Ceramic Society, (94), 12, 4556-4561.

which has been published in final form at: http://dx.doi.org/10.1111/j.1551-2916.2011.04896.x

Copyright: Wiley-Blackwell

http://eu.wiley.com/WileyCDA/Brand/id-35.html

Postprint available at: Linköping University Electronic Press

http://urn.kb.se/resolve?urn=urn:nbn:se:liu:diva-75292 


\title{
On the Topotactic Transformation of $\mathrm{Ti}_{2} \mathrm{AlC}$ into a Ti-C-O-F Cubic Phase by Heating in Molten Lithium Fluoride in Air
}

Michael Naguib, ${ }^{\dagger, \ddagger}$ Volker Presser, ${ }^{\dagger, \dagger}$ Darin Tallman, ${ }^{\dagger}$ Jun Lu, ${ }^{\S}$ Lars Hultman ${ }^{\S}$, Yury Gogotsi, ${ }^{\dagger,}$ and Michel W. Barsoum ${ }^{\dagger, *}$

$\dagger$ Department of Materials Science and Engineering, Drexel University, Philadelphia, Pennsylvania 19104.

A. J. Drexel Nanotechnology Institute, Drexel University, Philadelphia, Pennsylvania 19104

$\S$ Thin Film Physics Division, Department of Physics (IFM), Linköping University, S-583 31 Linköping, Sweden.

\begin{abstract}
Herein we report on the formation of a Ti-C-O-F phase via the topotactic transformation of $\mathrm{Ti}_{2} \mathrm{AlC}$ by immersion in molten lithium fluoride, $\mathrm{LiF}$, at $900^{\circ} \mathrm{C}$ in air for $2 \mathrm{~h}$. The $\mathrm{Al}$ diffuses out of the structure and reacts with $\mathrm{LiF}$ to form $\mathrm{Li}_{3} \mathrm{AlF}_{6}$. X-ray diffraction, Raman spectroscopy, optical, scanning and transmission electron microscopy with energy-dispersive spectroscopy showed the selective etching of $\mathrm{Al}$ from the structure and the formation of a cubic, rock-salt, Ti$\mathrm{C}-\mathrm{O}-\mathrm{F}$ phase. The transformation is topotaxial, involves de-twinning of the hexagonal $\mathrm{Ti}_{2} \mathrm{AlC}$ structure and results in domains that are of the order of $10 \mathrm{~nm}$. The reaction rate is significantly higher when the reaction is carried out in air than when it is carried out in vacuum.
\end{abstract}

Keywords: $\mathrm{Ti}_{2} \mathrm{AlC}, \mathrm{LiF}$, topotactic transformation

This work was supported by the Assistant Secretary for Energy Efficiency and Renewable Energy, Office of Vehicle Technologies of the U.S. Department of Energy under Contract No. DE-AC02-05CH11231, Subcontract 6951370 under the Batteries for Advanced Transportation Technologies (BATT) Program. *Author to whom correspondence should be addressed. Email: barsoumw @ drexel.edu 


\section{Introduction}

The ternary carbides and nitrides with a $\mathrm{M}_{n+1} \mathrm{AX}_{n}$ chemistry - where $n=1,2$, or 3 , $\mathrm{M}$ is an early transition metal, $\mathrm{A}$ is an A-group element (mostly groups 13 and 14), and $\mathrm{X}$ is $\mathrm{C}$ or $\mathrm{N}-$ represent a family of more than 60 members. ${ }^{1}$ These phases are layered hexagonal (space group $\mathrm{P}_{3} / \mathrm{mmc}$ ), with two formula units per unit cell. In the crystal structure, near close-packed $\mathrm{M}$ atom layers are interleaved with layers of group A elements; the $\mathrm{X}$ atoms fill the octahedral sites between the former (Fig. 1a).

The main motivation of this work was to try and create two-dimensional, 2-D, $M_{n+1} X_{n}$ structures by the selective removal of the A-element for a host of potential applications, the most important of which is the use of these materials as anodes in Li-ion batteries. We recently have shown that immersing $\mathrm{Ti}_{3} \mathrm{AlC}_{2}$ powders in concentrated $\mathrm{HF}$ solutions resulted in the selective etching of the $\mathrm{Al}$ and the formation of $\mathrm{Ti}_{3} \mathrm{C}_{2}(\mathrm{OH})_{2}$ and possibly $\mathrm{Ti}_{3} \mathrm{C}_{2} \mathrm{~F}_{2}{ }^{2}$ In another set of experiments we have shown that chlorination of select MAX phases resulted in the etching of both the $\mathrm{M}$ and $\mathrm{A}$ elements, which in turn resulted in carbide-derived carbons (CDCs) with unique characteristics. $3 ; 4$

By now it is well established that since the A-group layers in the MAX phases are more weakly bound that the stronger strong $\mathrm{M}-\mathrm{X}$ bonds, ${ }^{5}$ they are more reactive. Heating $\mathrm{Ti}_{3} \mathrm{SiC}_{2}$ in carburizing atmosphere results in the out-diffusion of $\mathrm{Si}$ and the formation of $\mathrm{TiC}_{\mathrm{x}}{ }^{6}$ the same was observed when heating $\mathrm{Ti}_{3} \mathrm{SiC}_{2}$ in molten $\mathrm{Al}{ }^{7}$ Heating, to relatively high temperatures, under vacuum also results in decomposition of the MAX phase into "MX" (transition metal carbide) and "A" (A-group metal). Examples include the heating of $\mathrm{Ti}_{2} \mathrm{InC}$ to $800^{\circ} \mathrm{C}$ under 
vacuum. ${ }^{8}$ and the decomposition of $\mathrm{Ti}_{3} \mathrm{SiC}_{2}$ thin films in vacuum ${ }^{9}$ Zhou et al. ${ }^{10}$ who studied the crystallographic relations between $\mathrm{Ti}_{3} \mathrm{SiC}_{2}$ and $\mathrm{TiC}$ and found that removing $\mathrm{Si}$ from $\mathrm{Ti}_{3} \mathrm{SiC}_{2}$ resulted in the formation of a cubic substoichiometric transition metal carbide $\left(\mathrm{TiC}_{0.67}\right)$.

More germane to this work, however, is previous work in which we showed that when $\mathrm{Ti}_{3} \mathrm{SiC}_{2}$ was immersed in molten cryolite $\left(\mathrm{Na}_{3} \mathrm{AlF}_{6}\right)$ at $960^{\circ} \mathrm{C}$ it converted to a cubic rock salt phase, $\mathrm{Ti}\left(\mathrm{C}_{0.67} \mathrm{Si}_{0.06}\right) .{ }^{11}$ The transformation was topotactic, and occurred by the outward diffusion $\mathrm{Si}$ (e.g. Fig. 1b) and the de-twinning of alternate $\mathrm{Ti}_{3} \mathrm{C}_{2}$ layers (see Fig. 1c). We also presented some evidence that the vacancies, in the resulting $\mathrm{Ti}_{3} \mathrm{C}_{2}$ phase, were partially ordered. Herein we report on a similar transformation of $\mathrm{Ti}_{2} \mathrm{AlC}$ into a $\mathrm{TiC}_{0.5+\mathrm{x}}$ phase - rich in oxygen and fluorine when the former is immersed in molten lithium fluoride, $\mathrm{LiF}$, at $900^{\circ} \mathrm{C}$.

\section{Experimental Procedure}

Both powder (> 92 vol.\%, -325 mesh, Sandvik-Kanthal, Sweden) and bulk $\mathrm{Ti}_{2} \mathrm{AlC}$ samples were used. The processing details of making the bulk $\mathrm{Ti}_{2} \mathrm{AlC}$ samples can be found elsewhere. ${ }^{12}$ In short, a stoichiometric mixture of $\mathrm{Ti}, \mathrm{Al}_{4} \mathrm{C}_{3}(99 \%$, Alfa Aesar, Ward Hill, USA) and graphite (99\%, Alfa Aesar, Ward Hill, USA) powders was mixed and hot pressed for 4 h under vacuum at $1600{ }^{\circ} \mathrm{C}$ under a load corresponding to a stress of $40 \mathrm{MPa}$. The resulting sample was predominantly single phase and fully dense.

Roughly $10 \mathrm{~g}$ of $\mathrm{Ti}_{2} \mathrm{AlC}$ powder were mixed with $\approx 30 \mathrm{~g}$ of $\mathrm{LiF}$ powder $(99 \%$, Alfa Aesar, Ward Hill, USA) and heated to $900{ }^{\circ} \mathrm{C}$ for $2 \mathrm{~h}$ in air in a platinum, Pt, crucible. After cooling, the resultant powder was investigated by X-ray diffraction (XRD) with a diffractometer (Siemens D500, Bruker AXS, Karlsruhe, Germany) using $\mathrm{Cu} \mathrm{K}_{\alpha}$ radiation, and a step scan of $0.02^{\circ}$ and $1 \mathrm{~s}$ per step. When possible, Si powder (99\%, Alfa Aesar, Ward Hill, USA) was used as an internal 
standard. To induce preferred orientation, the resulting powders were cold pressed to $1 \mathrm{GPa}$ into $\approx 300 \mu \mathrm{m}$ thin, $2.5 \mathrm{~cm}$ diameter disks.

Bulk samples were also immersed in molten $\mathrm{LiF}$ at $900{ }^{\circ} \mathrm{C}$ for $2 \mathrm{~h}$. Upon cooling, the bulk samples were cleaned by gently grinding off the solidified salt, and their surfaces investigated by XRD. The bulk samples were also cross-section, mounted, ground, and polished - down to $1 \mu \mathrm{m}$ - and observed under an optical microscope, OM, (S8AP0: Leica Microsystems Inc., Bannockburn, IL, USA) and a scanning electron microscope, SEM, (Supra 50VP, Zeiss, Oberkochen, Germany) equipped with an energy-dispersive spectrometer, EDS, (Oxford Inca XSight, Oxfordshire, UK).

Raman spectroscopic investigation of the samples was carried out on an inVia Raman microspectrometer (Renishaw plc, Gloucestershire, UK) using an Ar-ion laser (488.0 nm) and a grating with 1800 lines $/ \mathrm{mm}$. This corresponds to a spectral resolution of $1.9 \mathrm{~cm}^{-1}$ and a spot size of $0.7 \mu \mathrm{m}$ in the focal plane. Transmission electron microscopes, TEM, (JEOL JEM-2010F and JEM 2010, Japan) operating at $200 \mathrm{kV}$ were used to characterize the exfoliated powders. EDS analysis in the TEM was carried out using an ultra-thin window X-ray energy dispersive spectrometer, EDAX (EDAX, Mahwah, NJ). The as-processed material was characterized using a TEM (FEI, Tecnai G2 TF20UT FEG, The Netherlands) with EDS analysis.

The Vickers microhardness, at $10 \mathrm{~N}$, of the reaction layer was also measured using a microhardness tester (LECOM 400, LECO Corp., St. Joseph, MI, USA).

\section{Results and Discussion}

The XRD pattern of the unreacted powders (Fig. 2a) show only peaks belonging to LiF and $\mathrm{Ti}_{2} \mathrm{AlC}$, with a small amount of $\mathrm{TiC}$ present as an impurity in the starting $\mathrm{Ti}_{2} \mathrm{AlC}$ powder. After treatment, the $\mathrm{Ti}_{2} \mathrm{AlC}$ peaks disappear and are replaced by broad peaks whose positions (dashed 
lines in Fig. 2b, c and d) correspond to those of $\mathrm{TiC}_{\mathrm{x}}$. Using the Scherrer formula, ${ }^{13}$ the average grain size after treatment is estimated to be $10 \pm 3 \mathrm{~nm}$. The XRD spectra of the treated powders show additional peaks for $\mathrm{LiF}$ and $\mathrm{Li}_{3} \mathrm{AlF}_{6}$. The $\mathrm{TiC}$ lattice parameters are $4.29 \pm 0.02 \AA$ for the powders (Figs. $2 \mathrm{c}$ and d) and $4.30 \pm 0.03 \AA$ for the bulk (Fig. 2b). Note the bulk XRD contains much less ancillary phases.

OM images of the bulk reacted samples (Figs. $3 \mathrm{a}, \mathrm{b}$, and c), clearly show $\mathrm{a} \approx 200-400 \mu \mathrm{m}$ thick reaction zone. At higher magnification, of an area comprising the interface between the reacted and un-reacted zones (Fig. 3b), it is clear that the grain boundaries in the former are better delineated. The grain boundaries in the reacted region appear as if they had been etched, when, in fact they had not been.

The topotactic nature of the reaction is also incontrovertible. After the reaction, the original sharp corner (top left in Fig. 3a) of the bulk sample is preserved, and the grains do not change shape upon reaction.

The etching effect can also be seen in a SEM micrograph (Fig. 4a and top inset). A higher magnification SEM micrograph (bottom inset in Fig. 4a) shows that the exfoliation of the basal planes is occurring at quite a fine scale indeed.

EDS of the area delineated by the vertical rectangle in Fig. 4a is shown in Fig. 4b. The concentration profiles confirm that the affected zone is depleted in $\mathrm{Al}$, and rich in $\mathrm{F}$ and $\mathrm{O}$. The average chemistry of the outermost layer - delineated by the horizontal rectangle in Fig. 4a translates to $\approx \mathrm{TiC}_{0.5} \mathrm{O}_{0.4} \mathrm{~F}_{0.5} \mathrm{Al}_{0.1}$. In the unaffected area, EDS confirmed the 211 chemistry, viz., $\mathrm{Ti}_{2} \mathrm{Al}_{0.96} \mathrm{C}_{0.92}$. This result in turn increases our confidence that the $\mathrm{C}$-levels reported herein are more or less accurate. The $\mathrm{Al}$ concentration is slightly higher near the surface, most probably due 
to contamination with $\mathrm{Li}_{3} \mathrm{AlF}_{6}$, goes through a minimum in the center of the reacted layer and increases to $\approx 25$ at. $\%$ in the bulk. The opposite is true of the $\mathrm{O}$ and $\mathrm{F}$ concentrations.

Figure 5a shows a TEM micrograph of a $\mathrm{TiC}_{\mathrm{x}}$ flake. The lacey nature of the flake with fine cracks and delaminations and kink bands - again at the nanoscale - are obvious. EDS of that area (Fig. 5b) shows the presence of Ti, C, O and F, but little to no Al. Twinned domains with respect to the TiC matrix is indicated in the SAD pattern shown in Fig. 5c.

Figure 6a shows a HRTEM image of a heavily twinned region. Figures $6 \mathrm{~b}$ and $\mathrm{c}$ are higher magnifications of regions outlined by rectangles in Fig. 6a. A closer inspection of the lattice in Fig. 6a reveals the presence of several twin boundaries. While some twin boundaries have perfect coherency (c.f. Fig. 6b), most are incoherent and consist of atom columns with a dumbbell appearance as in a stacking fault while maintaining coherence with the lower and upper parts of the twinned material across the boundary (c.f. Fig. 6c). Some of the incoherent twin boundaries are terminated in the basal plane by partial dislocations as indicated in the left lower portion of Fig. 6a by an inverted T's.

When the Raman spectra of $\mathrm{Ti}_{2} \mathrm{AlC}$ (Fig. 7a), $\mathrm{Ti}_{3} \mathrm{AlC}_{2}$ (Fig. 7b) and a grain in the reacted zone (Figs. 7c) are compared the following observations are salient: a) for the most part, the peaks at $\omega_{3}$, and $\omega_{4}$ disappear after reaction; b) the peaks $\omega_{5}$ and $\omega_{6}$ appear to merge, down-shift to a frequency $\omega_{7}$, at about $617 \mathrm{~cm}^{-1}$ shown by the dashed vertical line in Fig. 7 ; c) the peaks after reaction are considerably wider. The Raman spectrum (Fig. 7d) of the edge of a grain that appeared partially reacted (colored grain in Fig. 3b) contains peaks belonging to both $\mathrm{Ti}_{2} \mathrm{AlC}_{\mathrm{C}}$ and those of the reaction product.

The Vickers microhardness of the reacted layer was $3 \pm 0.2 \mathrm{GPa}$. 
From the EDS and XRD results it is reasonable to conclude that the following, simplified, reaction occurs when $\mathrm{Ti}_{2} \mathrm{AlC}$ is immersed in molten $\mathrm{LiF}$ :

$$
0.5 \mathrm{Ti}_{2} \mathrm{AlC}+3.44 \mathrm{LiF}+0.72 \mathrm{O}_{2}=\mathrm{TiC}_{0.5} \mathrm{O}_{0.4} \mathrm{~F}_{0.5} \mathrm{Al}_{0.1}+0.5 \mathrm{Li}_{3} \mathrm{AlF}_{6}+\mathrm{Li}_{2} \mathrm{O}
$$

This reaction is simplified in that it assumes the Ti: $\mathrm{C}$ ratio to be $2: 1$ when it is not (see below). It also assumes that the O:F:Al ratios to be fixed, when in fact, these values differ from grain to grain. At this juncture it is important to note the important role oxygen plays in this reaction. At $\approx 20 \mu \mathrm{m}$, the reaction layer formed when a bulk sample was heated in a vacuum hot press (not shown) for $8 \mathrm{~h}$ is significantly thinner than the one that formed in air after $2 \mathrm{~h}$ at the same temperature (Fig. 3a). These results are not surprising since it is well established that oxygen plays a key role when metals react with fluoride salts. ${ }^{14}$

Assuming the densities of the $\mathrm{Ti}_{2} \mathrm{AlC}, \mathrm{LiF}, \mathrm{TiC}_{0.5} \mathrm{O}_{0.4} \mathrm{~F}_{0.5} \mathrm{Al}_{0.1}, \mathrm{Li}_{3} \mathrm{AlF}_{6}$ and $\mathrm{Li}_{2} \mathrm{O}$ to be, respectively, $4.11,2.64,4.93,2.87$, and $2.01 \mathrm{Mg} / \mathrm{m}^{3}$, the molar volume change of reaction I is only $\sim-2 \%$. This mild volume change explains why, for the most part, the reaction occurs with minimal cracking. This is most convincingly seen at the corner of the sample (Fig. 3a). Typically, when reaction volume changes are high, cracks nucleate at sharp corners. Their absence here thus confirms the small volume changes on reaction. The fine cracks and the etching of the grain boundaries, on the other hand, is consistent with the small volume shrinkage, calculated based on Eq. 1.

The lattice constant of the $\mathrm{TiC}_{\mathrm{x}}$ present in the bulk sample prior to $\mathrm{LiF}$ treatment, is $4.33 \AA$, which corresponds to an $\mathrm{x}$ of $\approx 1 .{ }^{15}$ The lattice parameter of the newly formed cubic phase, however, is $4.29 \AA$ in the case of the powders and $4.30 \AA$ in case of the bulk sample. Why the values are different is not clear at this time, but most probably due to the presence of oxygen 
and/or carbon deficiency. For a example, Zainulin et al. ${ }^{16}$ and Lavrenko, et. al. ${ }^{17}$ showed that the incorporation of $\mathrm{O}$ in the $\mathrm{TiC}$ lattice decreased the lattice parameter of the latter.

The full width at half maximum, FWHM, of the resulting phase peaks is significantly wider than that of the unreacted $\mathrm{TiC}$ in the starting $\mathrm{Ti}_{2} \mathrm{AlC}$ powder. Using the Scherer formula ${ }^{13}$ we estimate the average grain size to be $\approx 10 \mathrm{~nm}$. The fact that all peaks - not just the (111) peaks - are wider after reaction, implies that the reaction results in the breakdown of the original grains, in both the $a$ and $c$ directions of the original structure.

The HRTEM and SAD results in the TEM (Figs. 5, 6a and b) confirm the nanoscale of the resulting grains.

The angles $\left(\theta\right.$ and $\beta$ ) between the twined planes in the HRTEM (Fig. 6c) are $\sim 138^{\circ}$ and $110^{\circ}$ respectively. These values are close to those one would predict from the $\mathrm{Ti}_{2} \mathrm{AlC}$ structure (Fig. 1b) viz. $\sim 132^{\circ}$ and $111^{\circ}$, respectively. Both sets of values are also in agreement with the angles $\left(\theta^{\prime}\right.$, and $\left.\beta^{\prime}\right)$ in the $\operatorname{SAD}$ (Fig. 5c) pattern that are $\sim 70^{\circ}$ and $39^{\circ}$, respectively (viz. $\theta^{\prime} \approx 180-$ $\left.\theta, \beta^{\prime} \approx 180-\beta\right)$.

As important, the SAD results showed two sets of spots with an angle of $39^{\circ}$ between them. This angle is consistent with the de-twining of the hexagonal structure upon the formation of the cubic phase. In this sense, these results are in complete agreement with previous work. ${ }^{11}$ How the de-twining of few layers in one direction and others in the opposite direction occurs remains a mystery. The reasons for the de-twinning, however, is not; TiC does not form twins readily because its stacking fault energy is quite high. Our finding of the stacking fault nature of the twin boundary in TiC during de-twinning (Fig. 6c) sheds important new light to our understanding of de-twinning in this system. The stacking fault, with associated partial dislocations, if glissile could explain the de-twinning. Another possibility is the presence of thin 
intergrown $\mathrm{TiC}$ platelet in the initial $\mathrm{Ti}_{2} \mathrm{AlC}$ sample. Liu et $a{ }^{18}{ }^{18}$ showed that these platelets exist in $\mathrm{Ti}_{2} \mathrm{AlC}$ with the following orientation:(0001) $\mathrm{Ti}_{2} \mathrm{AlC} / /(111) \mathrm{TiC}$. It is thus possible that the transformation of the $\mathrm{Ti}_{2} \mathrm{AlC}$ into the cubic phase, two directions one for the initial $\mathrm{TiC}$ and the second for transformed $\mathrm{Ti}_{2} \mathrm{AlC}$ are present. Also it was reported that inducing "A" element (as $\mathrm{Si})$ in $\mathrm{TiC}$ result in microtwins ${ }^{19}$ so some microtwin may exist in the $\mathrm{TiC}$ platelets from the beginning before the reaction.

Spanier et al. ${ }^{20}$ have shown that the peaks at $\omega_{1}$ to $\omega_{4}$ (Figs. $7 \mathrm{a}$ and $\mathrm{b}$ ), are due to vibrations of the $\mathrm{Al}$ atoms in $\mathrm{Ti}_{2} \mathrm{AlC}$ or $\mathrm{Si}$ atoms in $\mathrm{Ti}_{3} \mathrm{SiC}_{2}$. It is thus not surprising that these peaks all but disappear after reaction (Fig. 7c). The peaks at $\omega_{5}$ and $\omega_{6}$ are due to the vibrations of the Catoms; those peaks do not appear in the 211 MAX structure; they only appear in the 312 and 413 phases. It is thus not unreasonable to assume the peak, $\omega_{7}$ at $617 \mathrm{~cm}^{-1}$ (Fig. 7c) - that emerges after reaction - is also related to the vibration of the C-atoms. This peak can be assumed to be due to the merging of peaks $\omega_{5}$ and $\omega_{6}$ and their downshifting due to the presence of ordered vacancies on the Al-sublattice (Fig. 1b). Such downshifting has been observed in Raman spectra of very thin layers of inorganic layered compounds. ${ }^{21}$ Furthermore, line broadening and the spectral shifts in the Raman spectra are consistent with structural deterioration and loss of crystallinity as evidenced from the broadened XRD profiles. Indeed, less affected grains (Fig. 7d) show narrower linewidths. The nature of the peak at $\omega_{8}$ (Fig. 7d) is unclear at this time, but is most probably related to defects - most probably vacancies. What role that $\mathrm{F}$ and $\mathrm{O}$ atoms play in the Raman spectra, and where they reside is unclear and beyond the scope of this work. This comment notwithstanding, oxygen atoms most probably form a solid solution $\mathrm{TiC}_{\mathrm{x}} \mathrm{O}_{\mathrm{y}}$, whereas fluorine can be terminating the surface of the particles. 
In cubic $\mathrm{TiC}_{\mathrm{x}}$ with random vacancies, the (111) plane's intensity is higher than that of the (200) planes. ${ }^{15}$ In the reaction product created herein, these peak intensities are reversed. This reversal was previously ascribed to vacancy ordering, ${ }^{7}$ and there is no reason to believe that the situation herein is any different.

The hardness of near stoichiometric $\mathrm{TiC}$ is $\approx 30 \mathrm{GPa} ;{ }^{22}$ the microhardness of the oxicarbide is even higher. ${ }^{17}$ Reducing the $\mathrm{C}$-content to 0.58 , viz. $\mathrm{TiC}_{0.58}$, reduces the hardness to $\sim 12 \mathrm{GPa}^{23}$ Given that the hardness of the reaction layer produced herein is $3 \pm 0.2 \mathrm{GPa}$, it is unlikely that the vacancies are not ordered. As far as we are aware this is by far the lowest hardness value ever reported for $\mathrm{TiC}_{\mathrm{x}}$. This comment notwithstanding, one reason for the lower hardness is the presence of the very fine delaminations parallel to the original basal planes of the $\mathrm{Ti}_{2} \mathrm{AlC}$ (Fig. 5a and lower inset in Fig. 4a), which can be taken as another manifestation of ordering. More importantly, these powders differ from conventional $\mathrm{TiC}_{\mathrm{x}}$, in that they have sufficient ductility/plasticity to allow them to be cold pressed into free-standing thin discs that can be easily handled, etc.

The material described herein, viz. two-dimensional Ti-C-O-F nanoparticles, offers a large number of prospective applications, especially when considering that the MAX phase precursor can be manufactured in various forms ranging from powder, monolithic materials, thin films, etc. With a low surface energy, oxyfluorcarbides have recently been shown to be useful as anti-stain coatings. ${ }^{24}$ This nano Ti-C-O-F phase may also be used as an absorbent for environmental pollutants. ${ }^{25}$ While the carbon content results in optically non-transparent samples and, therefore, the low polarizability of oxyfluorides cannot be used, the material's high Lewis acidity ${ }^{26}$ may enable a wide range of catalyst applications. Further given the unique photo-catalytic properties of $\mathrm{TiO}_{2}$ doped with carbon, ${ }^{27 ; 28}$ the novel Ti-C-O-F nanophase reported herein may be utilized 
as bi-functional, opto-chemical coatings in complex shaped devices enabled by the formidable

machinability of MAX phases. Studies on Si-O-C materials ${ }^{29 ; 30}$ and $\mathrm{Si} / \mathrm{TiC}$ nanocomposites ${ }^{31 ; 32}$ have shown potential for lithium intercalation and the combination of nanosized domains and constitutional disorder in the lattice render this Ti-C-O-F phase particularly interesting for battery applications since it is possible to cold press this material, without the use of binders into free-standing electrodes that are quite conductive. Further investigation for the properties of this new chemistry is required which may have unique electronic properties.

\section{Conclusions}

When $\mathrm{Ti}_{2} \mathrm{AlC}$ is immersed in molten $\mathrm{LiF}$ at $900{ }^{\circ} \mathrm{C}$ for $2 \mathrm{~h}$ in air a topotactical transformation is induced that results is the formation of a $\mathrm{TiC}_{\mathrm{x}}$ cubic phase with where $\mathrm{x} \approx 0.5$, that contains significant amounts of $\mathrm{O}$ and $\mathrm{F}$ and small amounts of Al. Oxygen plays a crucial role in the reaction and it is likely that without it the reaction would not proceed. The Al diffuses out of the structure and reacts with $\mathrm{LiF}$ to form $\mathrm{Li}_{3} \mathrm{AlF}_{6}$. The vacancies in the resulting structure are ordered. Direct HRTEM evidence for de-twinning of the $\mathrm{Ti}_{n+1} \mathrm{C}_{n}$ blocks in the MAX phase is also presented. The volume change on reaction is small. We conclude from this that $\mathrm{Ti}_{2} \mathrm{AlC}$ cannot be used in molten halide salts, and more specifically LiF (especially in the presence of oxygen).

The combination of ordered vacancies, which, in turn, offer possibilities of exfoliation, together with the nanoscale structure and novel chemistry, viz. Ti-C-O-F, suggest many potential uses; uses that could span the gamut from photocalysis, to energy storage in batteries or supercapacitors, among others. 


\section{Acknowledgements}

This work was supported by the Assistant Secretary for Energy Efficiency and Renewable Energy, Office of Vehicle Technologies of the U.S. Department of Energy under Contract No. DE-AC02-05CH11231, Subcontract 6951370 under the Batteries for Advanced Transportation Technologies (BATT) Program. V.P. was supported by Alexander von Humboldt Foundation. Partial support was also provided by the Swedish Foundation for Strategic Research (SSF). Use of the SEM of the Centralized Research Facility (Drexel University) is acknowledged.

\section{References}

${ }^{1} \mathrm{M} . \mathrm{W}$. Barsoum, "The MN+1AXN phases: A new class of solids :

Thermodynamically stable nanolaminates," Progress in Solid State Chemistry, 28[1-4] 201-81 (2000).

${ }^{2}$ M. Naguib, M. Kurtoglu, V. Presser, J. Lu, J. Niu, M. Heon, L. Hultman, Y. Gogotsi, and M. W. Barsoum, "Two-Dimensional Nanocrystals Produced by Exfoliation of $\mathrm{Ti}_{3} \mathrm{AlC}_{2}, "$ Advanced Materials DOI: 10.1002/adma.2011023062 (2011).

${ }^{3}$ E. N. Hoffman, G. Yushin, M. W. Barsoum, and Y. Gogotsi, "Synthesis of CarbideDerived Carbon by Chlorination of $\mathrm{Ti}_{2} \mathrm{AlC}$, "Chemistry of Materials, 17[9] 2317-22 (2005).

${ }^{4}$ G. Yushin, E. Hoffman, A. Nikitin, H. Ye, M. Barsoum, and Y. Gogotsi, "Synthesis of nanoporous carbide-derived carbon by chlorination of titanium silicon carbide," Carbon, 43[10] 2075-82 (2005).

${ }^{5}$ M. W. Barsoum, "Physical Properties of the MAX Phases," pp. 1-11. in Encyclopedia of Materials: Science and Technology. Edited by C. Editors in, xA, J. K. H, xFc, B. rgen, 
W. C. Robert, C. F. Merton, I. Bernard, J. K. Edward, M. Subhash, V. Patrick, xE, and re. Elsevier, Oxford, 2006.

${ }^{6}$ T. El-Raghy and M. W. Barsoum, "Diffusion Kinetics of the Carburization and Silicidation of $\mathrm{Ti}_{3} \mathrm{SiC}_{2}, "$ J. Appl. Phys., 83 112-19 (1998).

${ }^{7 T}$. El-Raghy, M. W. Barsoum, and M. Sika, "Reaction of $\mathrm{Al}$ with $\mathrm{Ti}_{3} \mathrm{SiC}_{2}$ in the 8001000 C Temperature Range," Mater. Sci. Eng. A, 298174 (2001).

${ }^{8}$ M. W. Barsoum, J. Golczewski, H. J. Siefert, and F. Aldinger, "Fabrication and electrical and thermal properties of $\mathrm{Ti}_{2} \mathrm{InC}, \mathrm{Hf}_{2} \mathrm{InC}$ and (Ti,Hf) ${ }_{2} \mathrm{AlC}, " J$. Alloys and Compds., 340 173-79 (2002).

9J. Emmerlich, D. Music, P. Eklund, O. Wilhelmsson, U. Jansson, J. M. Schneider, H. Högberg, and L. Hultman, "Thermal stability of Ti3SiC2 thin films," Acta Materialia, 55[4] 1479-88 (2007).

${ }^{10}$ Y. Zhou and Z. Sun, "Crystallographic relations between $\mathrm{Ti}_{3} \mathrm{SiC}_{2}$ and $\mathrm{TiC}, "$ Materials Research Innovations, 3[5] 286-91 (2000).

11M. W. Barsoum, T. El-Raghy, L. Farber, M. Amer, R. Christini, and A. Adams, "The Topotaxial Transformation of $\mathrm{Ti}_{3} \mathrm{SiC}_{2}$ To Form a Partially Ordered Cubic $\mathrm{TiC}_{0.67}$ Phase by the Diffusion of Si into Molten Cryolite," J. Electrochem. Soc., 146[10] 3919-23 (1999).

${ }^{12}$ M. W. Barsoum, D. Brodkin, and T. El-Raghy, "Layered machinable ceramics for high temperature applications," Scripta Materialia, 36[5] 535-41 (1997).

13B. D. Cullity, "Elements of X-ray diffraction." Addison-Wesley (1978).

${ }^{14}$ S. Delpech, C. Cabet, C. Slim, and G. S. Picard, "Molten Fluorides for Nuclear Applications," Materials Today, 1334 (2010). 
15M. C. Morris, H. F. McMurdie, E. H. Evans, B. Paretzkin, H. S. Parker, and N. C. Panagiotopoulos, "National Bureau of Standards Monograph 25," pp. 110. in Standard Xray Diffraction Powder Patterns. Edited by C. R. Hubbard. NATIONAL BUREAU OF STANDARDS, Washingto, DC, 1981.

16Y. G. Zainulin, S. I. Alyamovsky, and G. P. Shveikin, "Concerning the structural mechanism of oxygen inclusion into the lattice of titanium carbide," Journal of Physics and Chemistry of Solids, 39[1] 29-31 (1978).

17V. A. Lavrenko, L. A. Glebov, A. P. Pomitkin, V. G. Chuprina, and T. G. Protsenko, "High-temperature oxidation of titanium carbide in oxygen," Oxidation of Metals, 9[2] 171-79 (1975).

18Z. J. Lin, M. J. Zhuo, Y. C. Zhou, M. S. Li, and J. Y. Wang, "Microstructural characterization of layered ternary Ti2AlC," Acta Materialia, 54[4] 1009-15 (2006).

${ }^{19}$ R. Yu, Q. Zhan, L. L. He, Y. C. Zhou, and H. Q. Ye, "Si-induced twinning of TiC and formation of Ti3SiC2 platelets," Acta Materialia, 50[16] 4127-35 (2002).

20J. Spanier, S. Gupta, M. Amer, and M. W. Barsoum, "Vibrational behavior of the $\mathrm{Mn}+1 \mathrm{AXn}$ phases from first-order Raman scattering $(\mathrm{M}=\mathrm{Ti}, \mathrm{V}, \mathrm{Cr}, \mathrm{A}=\mathrm{Si}, \mathrm{X}=\mathrm{C}, \mathrm{N}), "$ Physical Review B, 71[1] 012103 (2005).

${ }^{21}$ C. N. R. Rao and et al., "A study of the synthetic methods and properties of graphenes," Science and Technology of Advanced Materials, 11[5] 054502 (2010).

${ }^{22}$ G. De Maria, D. Ferro, L. D'Alessio, R. Teghil, and S. M. Barinov, "Hardness of titanium carbide films deposited on silicon by pulsed laser ablation," Journal of Materials Science, 36[4] 929-35 (2001). 
${ }^{23}$ D. Ferro, S. M. Barinov, J. V. Rau, A. Latini, R. Scandurra, and B. Brunetti, "Vickers and Knoop hardness of electron beam deposited $\mathrm{ZrC}$ and $\mathrm{HfC}$ thin films on titanium," Surface and Coatings Technology, 200[16-17] 4701-07 (2006).

${ }^{24}$ Venkataramani, "Low surface energy coatings for cooking products ". in, Vol. US2010/0009177 Edited by U. S. P. A. US2010/0009177, USA, 2010.

${ }^{25}$ H. Moriwaki, S. Kitajima, K. Shirai, K. Kiguchi, and O. Yamada, "Application of the powder of porous titanium carbide ceramics to a reusable adsorbent for environmental pollutants," Journal of Hazardous Materials, 185[2-3] 725-31 (2011).

${ }^{26}$ E. Kemnitz, Y. Zhu, and B. Adamczyk, "Enhanced Lewis acidity by aliovalent cation doping in metal fluorides," Journal of Fluorine Chemistry, 114[2] 163-70 (2002).

${ }^{27}$ M.-S. Wong, S.-W. Hsu, K. K. Rao, and C. P. Kumar, "Influence of crystallinity and carbon content on visible light photocatalysis of carbon doped titania thin films," Journal of Molecular Catalysis A: Chemical, 279[1] 20-26 (2008).

28I.-C. Kang, Q. Zhang, S. Yin, T. Sato, and F. Saito, "Preparation of a visible sensitive carbon doped $\mathrm{TiO}_{2}$ photo-catalyst by grinding $\mathrm{TiO}_{2}$ with ethanol and heating treatment," Applied Catalysis B: Environmental, 80[1-2] 81-87 (2008).

29J. Shen and R. Raj, "Silicon-oxycarbide based thin film anodes for lithium ion batteries," Journal of Power Sources, 196[14] 5945-50 (2011).

30P. E. Sanchez-Jimenez and R. Raj, "Lithium Insertion in Polymer-Derived Silicon Oxycarbide Ceramics," Journal of the American Ceramic Society, 93[4] 1127-35 (2010).

31Z. Y. Zeng, J. P. Tu, X. H. Huang, X. L. Wang, and J. Y. Xiang, "Electrochemical investigation on silicon/titanium carbide nanocomposite film anode for Li-ion batteries," Thin Solid Films, 517[17] 4767-71 (2009). 
32Z. P. Guo, Z. W. Zhao, H. K. Liu, and S. X. Dou, "Lithium insertion in Si-TiC nanocomposite materials produced by high-energy mechanical milling," Journal of Power Sources, 146[1-2] 190-94 (2005).

\section{Figure Captions}

Fig. 1. Schematic describing the process of transformation of $\mathrm{Ti}_{2} \mathrm{AlC}$ in $\mathrm{TiC}_{0.5}$ (a) $\mathrm{Ti}_{2} \mathrm{AlC}(\overline{2} 10)$ plane; (b) same as (a) but after removing the Al from the structure and, (c) same as (b) but after de-twinning of every other $\mathrm{TiC}_{0.5}$ slab. Angles $\theta$ and $\beta$ in (b) are the angles between de-twined planes

Fig. 2. XRD pattern before and after LiF treatment. The indexed $h k l$ reflections correspond to $\mathrm{Ti}_{2} \mathrm{AlC}$ in fig. $\mathbf{2 - a}$, and $\mathbf{T i C}_{\mathbf{x}}$ in 2-d. (a) $\mathrm{Ti}_{2} \mathrm{AlC}$ and $\mathrm{LiF}$ powder mixture before heating. (b) surface of a bulk sample after LiF treatment; (c) powder mixture after heating; (d) same as c, but after cold pressing. Note reversal of intensities of (111) and (200) peaks after cold pressing. Dashed lines represent the locations of the $\mathrm{TiC}_{\mathrm{x}}$ peaks.

Fig. 3. Cross-sectional OM micrographs of polished, bulk $\mathrm{Ti}_{2} \mathrm{AlC}$ sample after $\mathrm{LiF}$ treatment for $2 \mathrm{~h}$ at $900{ }^{\circ} \mathrm{C}$ in air, (a) low magnification, showing reaction layer and sharp corner after reaction. (b) Raman mapping in the affected zone; point (1) represent pure $\mathrm{Ti}_{2} \mathrm{AlC}$, (2) highly affected MAX (cf. Fig. 7c) and (3) partially transformed 211 (cf. Fig. 7d). The green (partially transformed) and red (fully transformed) colors corresponds with the degree of transformation. (c) High magnification OM image showed the etched-like grains.

Fig. 4. (a) Cross-sectiional SEM micrograph of bulk sample after the LiF treatment. Top inset shows higher magnification of reacted area. Lower inset, an even higher magnification of the 
same region; (b) EDS line mapping along the vertical rectangle in (a), the vertical line is dividing the graph in two parts (etched and not etched parts).

Fig. 5. (a) Bright field TEM image of a $\mathrm{TiC}_{\mathrm{x}}$ flake showing lacey nature of the reaction layer, (b) EDS spectrum of flake showing Ti, C, F and O, but no Al. (c) SAED pattern showing the presence of twins. The angles shown are the ones expected and plotted in Fig. 1b.

Fig. 6. a) HRTEM image showing two twins: a coherent twin on top and an incoherent twin in the middle with some dislocations shown as inverted T's. Inset shows the corresponding fast Fourier transform pattern again showing evidence for the presence of twins; (b) and (c) are enlarged images of the coherent and incoherent twins outlined by top and bottom rectangles in (a) respectively.

Fig. 7. Raman spectra of (a) $\mathrm{Ti}_{2} \mathrm{AlC}$, (b) $\mathrm{Ti}_{3} \mathrm{AlC}_{2}$, (c) fully reacted layer and, (d) partially reacted $\mathrm{Ti}_{2} \mathrm{AlC}$ grain. 
Figures

(a)

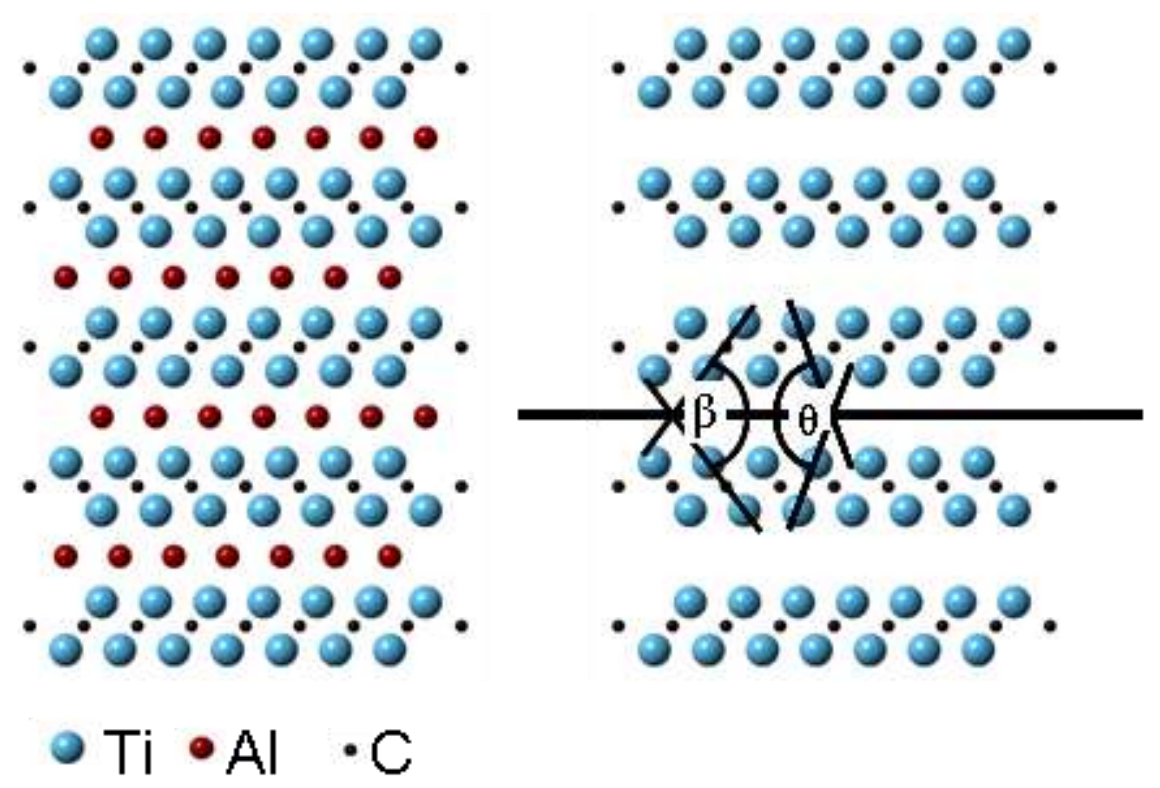

(c)

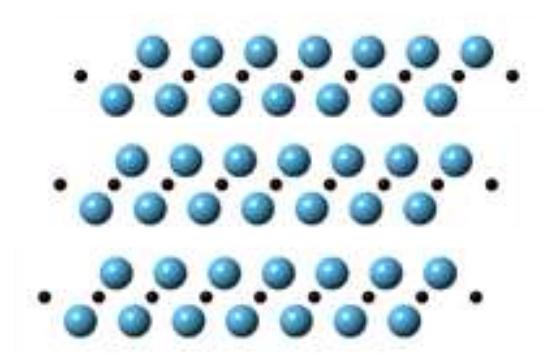

Fig. 1. Schematic describing the process of transformation of $\mathrm{Ti}_{2} \mathrm{AlC}$ in $\mathrm{TiC}_{0.5}$ (a) $\mathrm{Ti}_{2} \mathrm{AlC}(12 \mathrm{10})$ plane; (b) same as (a) but after removing the $\mathrm{Al}$ from the structure and, (c) same as (b) but after de-twinning of every other $\mathrm{TiC}_{0.5}$ slab. Angles $\theta$ and $\beta$ in (b) are the angles between de-twined planes 


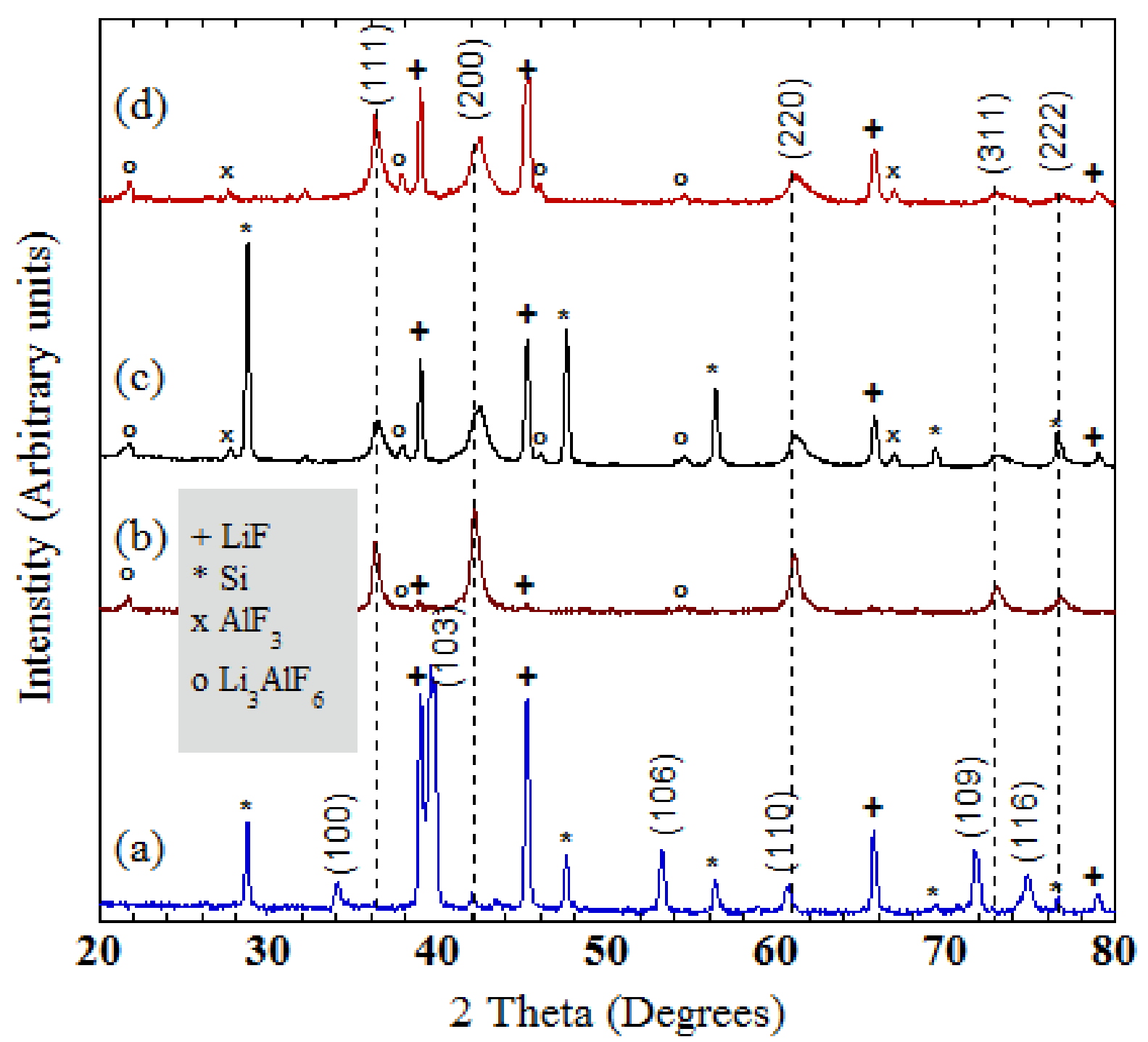

Fig. 2. XRD pattern before and after $\mathrm{LiF}$ treatment. The indexed $h k l$ reflections correspond to $\mathrm{Ti}_{2} \mathrm{AlC}$ in Fig. 2-a and $\mathrm{TiC}_{\mathbf{x}}$ in 2-d. (a) $\mathrm{Ti}_{2} \mathrm{AlC}$ and $\mathrm{LiF}$ powd er mixture before heating. (b) surface of a bulk sample after LiF treatment; (c) powder mixture after heating; (d) same as c, but after cold pressing. Note reversal of intensities of (111) and (200) peaks after cold pressing. Dashed lines represent the locations of the $\mathrm{TiC}_{\mathrm{x}}$ peaks. 

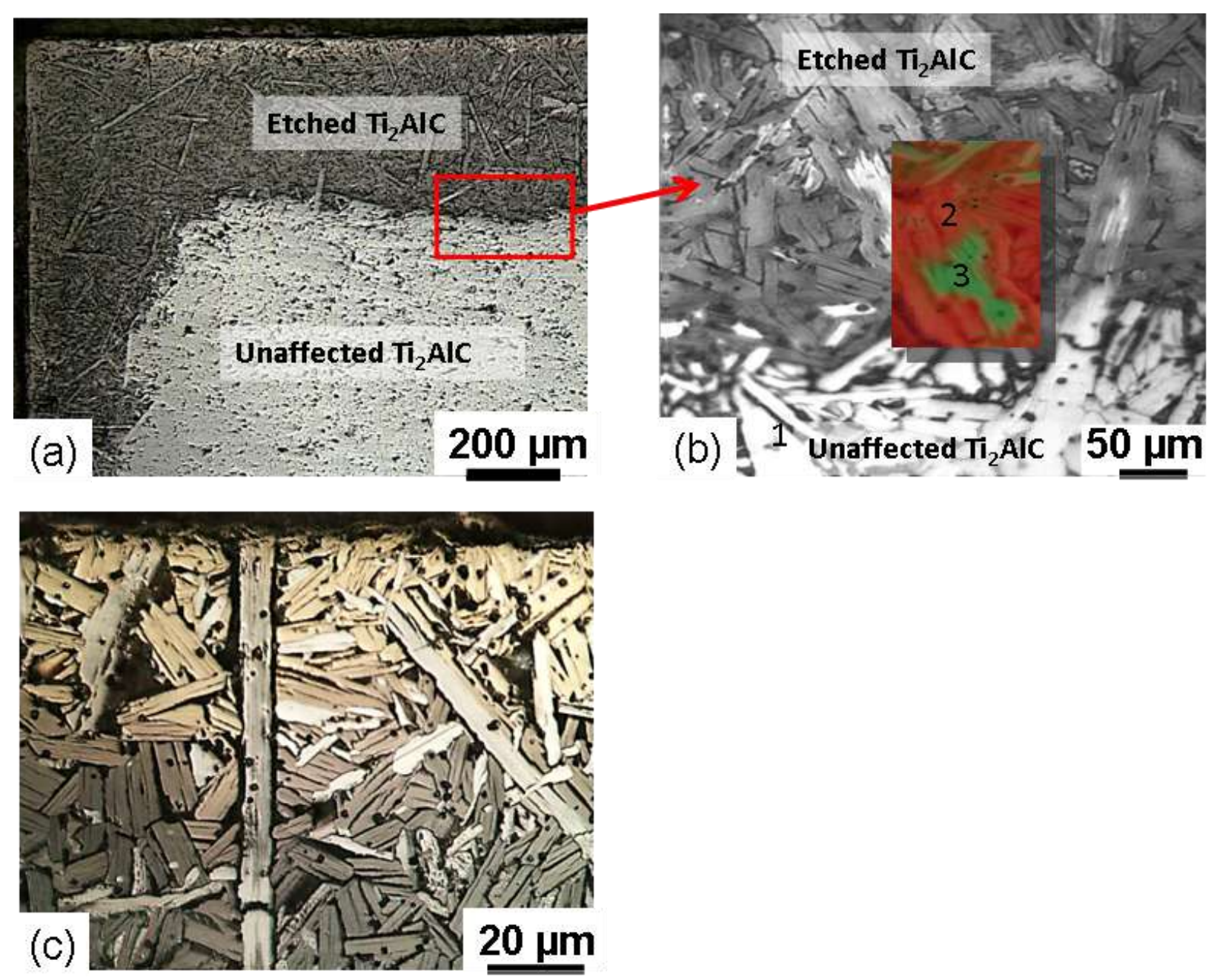

Fig. 3. Cross-sectional OM micrographs of polished, bulk $\mathrm{Ti}_{2} \mathrm{AlC}$ sample after $\mathrm{LiF}$ treatment for $2 \mathrm{~h}$ at $900{ }^{\circ} \mathrm{C}$ in air, (a) low magnification, showing reaction layer and sharp corner after reaction. (b) Raman mapping in the affected zone; point (1) represent pure $\mathrm{Ti}_{2} \mathrm{AlC}$, (2) highly affected MAX (cf. Fig. 7c) and (3) partially transformed 211 (cf. Fig. 7d). The green (partially transformed) and red (fully transformed) colors corresponds with the degree of transformation. (c) High magnification OM image showed the etched-like grains. 
(a)

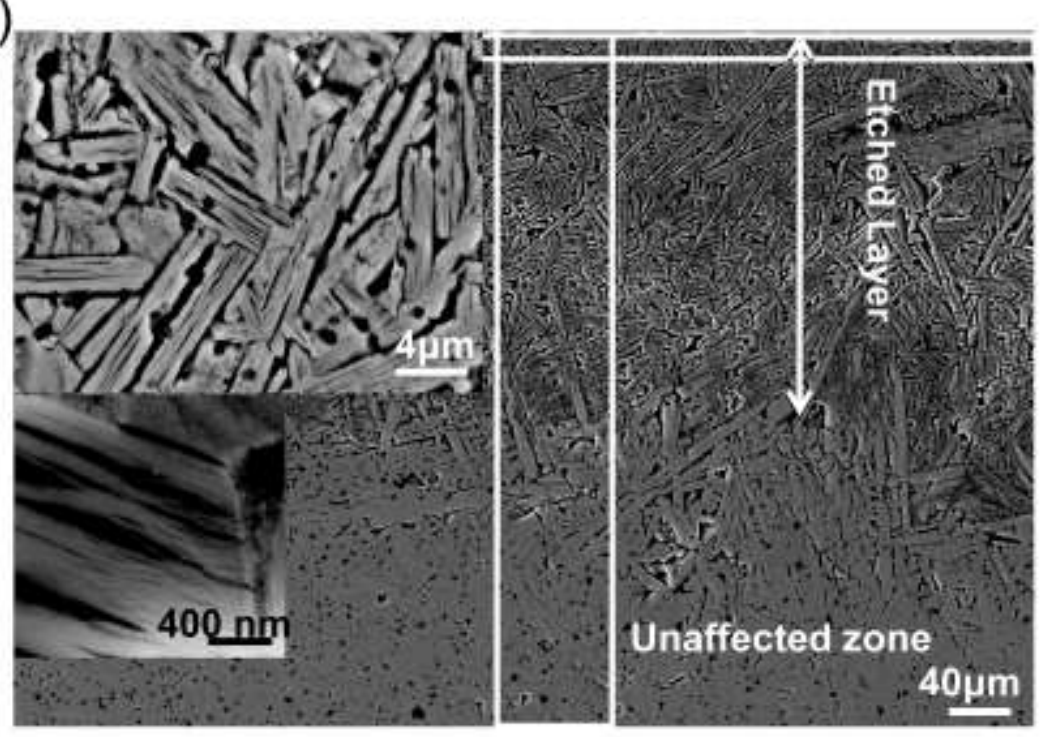

(b)

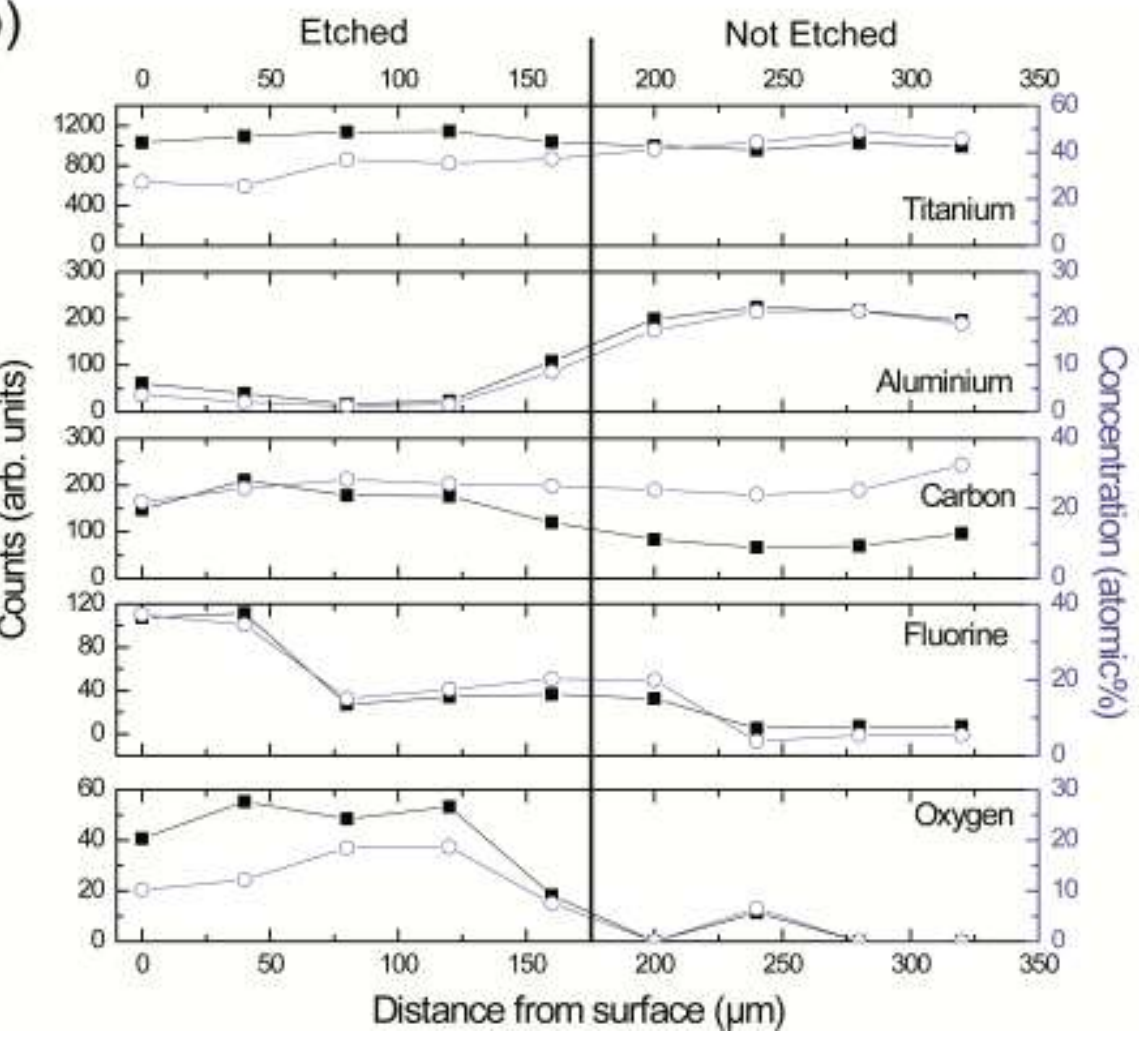

Fig. 4. (a) Cross-sectional SEM micrograph of bulk sample after the LiF treatment. Top inset shows higher magnification of reacted area. Lower inset, an even higher magnification of the same region; (b) EDS line mapping along the vertical rectangle in (a), the vertical line is dividing the graph in two parts (etched and not etched parts). 

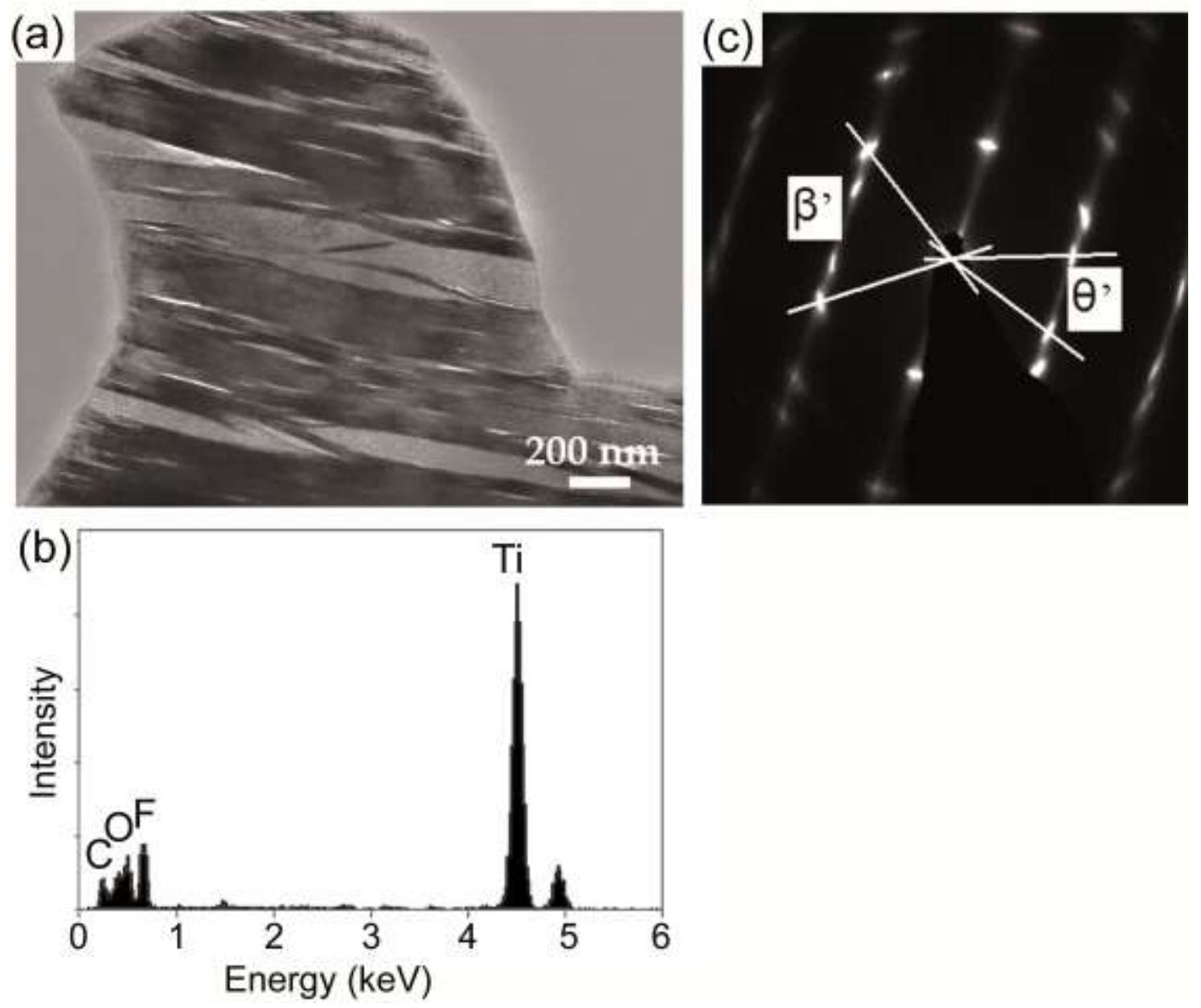

Fig. 5. (a) Bright field TEM image of a $\mathrm{TiC}_{\mathrm{x}}$ flake showing lacey nature of the reaction layer, (b) EDS spectrum of flake showing Ti, C, F and O, but no Al. (c) SAED pattern showing the presence of twins. The angles shown are the ones expected and plotted in Fig. 1b. 




Fig. 6. a) HRTEM image showing two twins: a coherent twin on top and an incoherent twin in the middle with some dislocations shown as inverted T's. Inset shows the corresponding fast Fourier transform pattern again showing evidence for the presence of twins; (b) and (c) are enlarged images of the coherent and incoherent twins outlined by top and bottom rectangles in (a) respectively. 


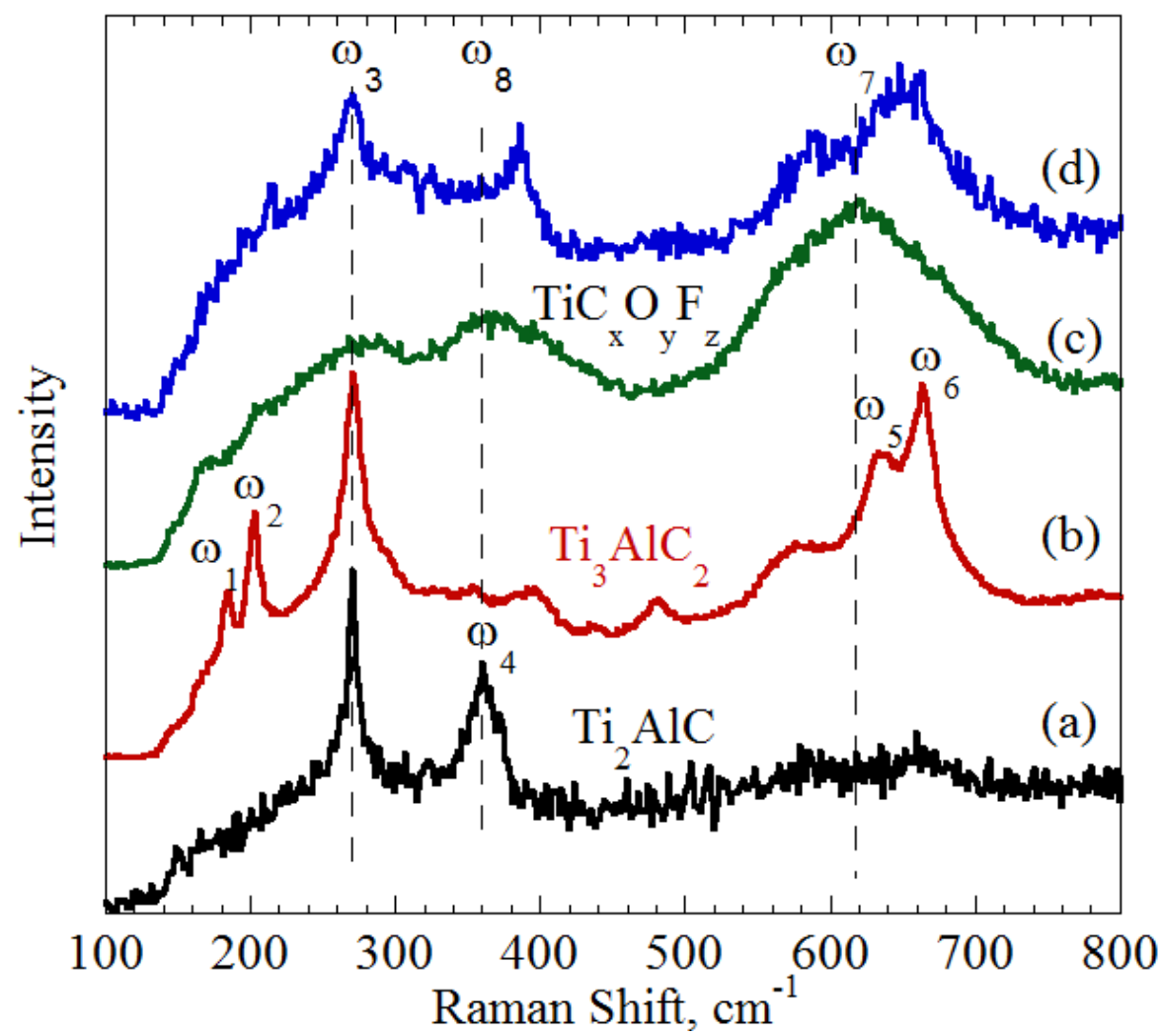

Fig. 7. Raman spectra of (a) $\mathrm{Ti}_{2} \mathrm{AlC}$, (b) $\mathrm{Ti}_{3} \mathrm{AlC}_{2}$, (c) fully reacted layer and, (d) partially reacted $\mathrm{Ti}_{2} \mathrm{AlC}$ grain. 